\title{
ACERTOS E CONTRADIÇÕES NA INTERPRETAÇÃO DA LEI 12.305/10 NOS PLANOS MUNICIPAIS DE GESTÃO INTEGRADA DE RESÍDUOS SÓLIDOS DA MICRORREGIÃO DE JABOTICABAL-SP
}

\author{
Patrícia Lopes Freire Pupin
}

Ana Claudia Giannini Borges ${ }^{2}$

\begin{abstract}
RESUMO
A Política Nacional de Resíduos Sólidos (PNRS) é o marco regulatório da questão do gerenciamento de resíduos no Brasil (Lei 12.305/10), que institui aos municípios a responsabilidade de elaborar plano de metas, ações e gerenciamento dos resíduos, que congregarão nos Planos Municipais de Gerenciamento Integrado de Resíduos Sólidos (PMGIRS). Assim, o artigo objetiva analisar os PMGIRS da microrregião de Jaboticabal-SP, e suas respectivas interpretações, a partir do artigo 19 da PNRS, que compreende o conteúdo mínimo necessário para a confecção dos Planos Municipais. Os planos destes municípios foram obtidos nas Secretarias e Departamentos responsáveis pela gestão dos Resíduos Sólidos de cada município. A partir das análises, obteve-se que: nenhum dos Planos foi fiel aos preceitos da PNRS; há significativas discrepâncias no texto dos Planos, quando comparados; há falta de concisão e clareza quanto às atribuições dos incisos e parágrafos da Lei; os prazos legais não foram cumpridos por alguns planos; e os relatos da situação dos resíduos sólidos nos municípios foram insuficientes.
\end{abstract}

PALAVRAS-CHAVE: Plano Nacional de Resíduos Sólidos. Planos Municipais. Microrregião de Jaboticabal-SP.

\footnotetext{
${ }^{1}$ Membro do "Projeto Suporte: apoio a organizações do terceiro setor e grupos da sociedade civil em seus processos de gestão", cadastrado na Pró-Reitoria de Extensão da Univ. Estadual Paulista UNESP. E-mail: patricialopesfreire@hotmail.com.

2 Doutora em Sociologia (FCLAr/UNESP) e Professora da Univ. Estadual Paulista - UNESP; Coordenadora do "Projeto Suporte: apoio a organizações do terceiro setor e grupos da sociedade civil em seus processos de gestão" - UNESP; Orientadora da pesquisa deste artigo. E-mail: agiannini@fcav.unesp.br.
} 


\title{
HITS AND CONTRADICTIONS IN THE INTERPRETATION OF LAW 12,305 / 10 PLANS OF MUNICIPAL SOLID WASTE MANAGEMENT INTEGRATED JABOTICABAL-SP MICRO- REGION
}

\begin{abstract}
The Brazilian National Solid Waste Policy (PNRS) is the regulatory framework for waste management issue in Brazil (Law 12,305 / 10), establishing the municipalities responsible for setting up goals plan, actions and management of waste, which gathered in Plans Integrated Municipal Solid Waste Management (PMGIRS). Thus, the article aims to analyze the PMGIRS the micro-region of Jaboticabal-SP, and their interpretations, from Article 19 of the PNRS, comprising the minimum amount necessary for the preparation of Municipal Plans. The plans of these municipalities were obtained in the secretariats and departments responsible for managing solid wastes in each municipality. From the analysis, it was found that: none of the plans was faithful to the precepts of PNRS; there are significant discrepancies in the text of the Plan compared; there is lack of conciseness and clarity regarding the responsibilities of sections and paragraphs of Law; the legal deadlines were not met by some plans; and reports the status of solid waste in the municipalities were insufficient.
\end{abstract}

\section{AJUSTES Y CONTRADICCIONES EN LA INTERPRETACIÓN DE LA LEY 12.305 / 10 PLANES DE MANEJO DE RESIDUOS SÓLIDOS MUNICIPALES INTEGRADO MICRORREGIÓN JABOTICABAL-SP}

\begin{abstract}
RESUMEN
La Política Nacional de Residuos Sólidos (PNRS) es el marco regulador de la cuestión de la administración de los residuos en Brasil (Ley 12.305/10), que insta a los municipios a la responsabilidad de elaborar un plan de metas, acciones y administración de los residuos que se congregarán en los Planos Municipales de Administración Integral de Residuos Sólidos (PMGIRS). Así, el artículo objetiva analizar los PMGIRS de la micro-región de Jaboticabal-SP y sus respectivas interpretaciones, según el artículo 19 de la PNRS, que incluye el contenido mínimo necesario para la confección de los Planos Municipales. Los planos de estos municipios fueron obtenidos en las Secretarias y departamentos responsables por la gestión de los Residuos Sólidos de cada municipio. Tras el análisis se concluye que: ningún Plano analizado ha sido fiel a los preceptos de la PNRS; existen significativas discrepancias en el texto de los Planos cuando comparados entre sí; hay falta de concisión y claridad respecto a las referencias de las secciones y párrafos de la Ley; los plazos legales no fueron cumplidos por parte de algunos Planos; y los informes de la situación de los residuos sólidos en los municipios fueron insuficientes.
\end{abstract}

PALABRAS CLAVE: Plan Nacional de Residuos Sólidos. Planos Municipales. Micro-región de JaboticabalSP. 


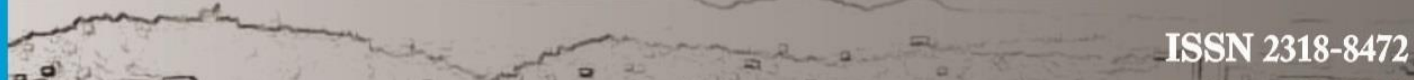

\section{Revista Nacional de}

Gerenciamento de Cidades

\section{1- INTRODUÇÃO}

Este artigo trata das propostas elaboradas em planos de metas e ações, dos municípios da microrregião de Jaboticabal-SP, para a questão do manejo de resíduos sólidos urbanos. Tais propostas são uma devolutiva da busca de soluções do Estado para regular o tema.

A questão dos resíduos sólidos (RS) provenientes da intensa atividade econômica e de consumo vem sendo tratada de forma mais ampla na sociedade.

Para Bernardes (2013, p. 197) "o consumo e a geração de resíduos estão mutuamente ligados". Estes produzem consequências ambientais, segundo Godecke et al. (2012, p. 1700), e que, portanto, há a necessidade de "combinação de instrumentos de comando e controle, econômicos e de comunicação [que] permite melhorias, desde que a gestão de resíduos urbanos seja percebida de forma sistêmica e holística."

Visto isso, o Estado busca recursos regulatórios para a temática, devido a sua responsabilidade sobre a demanda socioambiental (GODECKE et al., 2012; BERNARDES, 2013; GODOY, 2013). Após duas décadas de tramitação no Congresso Nacional, foi aprovado em 2010, a Lei 12.305 (BRASIL, 2010, caput) que institui a Política Nacional de Resíduos Sólidos (PNRS). Ela objetiva a "não geração, redução, reutilização, reciclagem e tratamento dos resíduos sólidos, bem como disposição final ambientalmente adequada dos rejeitos" (BRASIL, 2010, artigo $7^{\circ}$ ). Propõe, ainda, uma reformulação de valores dos consumidores, geradores e órgãos públicos, ao apontar que as formas de consumo sejam revalorizadas e reduzidas.

Godoy (2013, p. 3) contextualiza a dificuldade de se implantar diretrizes legais no Brasil antes da PNRS ser instituída: 


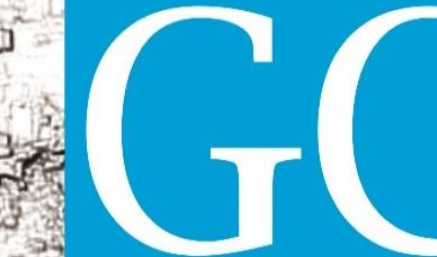

Revista Nacional de

Gerenciamento de Cidades

diferentes, às vezes, conflitantes entre si, emanados de órgãos públicos também diferentes, eram normas estabelecidas com objetivos diversos nos três níveis de poder e nos três poderes da República.

Para atender essa lacuna legal, a PNRS advém como o marco regulatório que estabelece uma gestão integrada entre as três esferas de governo (Federal, Estadual e Municipal), abrangendo ainda, as empresas privadas e a sociedade civil.

Na gênese dos entes responsabilizados estão os municípios que, através do texto da Lei, são considerados como o território objeto da aplicação regulatória dos RS gerados e descartados. Para tal, deve superar entraves da administração como explica Gomes e Steinbrück (2012, p. 106): "no momento, o foco do debate ainda está centrado nas limitações das prefeituras para desempenhar de forma adequada o seu papel em relação à gestão, coordenação e fiscalização dos resíduos sólidos."

No intuito de nortear as ações municipais (GOMES: STEINBRÜCK, 2012, p. 112), a PNRS declara que os mesmos devem elaborar plano de metas, ações e gerenciamento dos resíduos, que congregarão no Plano Municipal de Gerenciamento Integrado de Resíduos Sólidos (PMGIRS) e que deve ser implementados até 2 de agosto de 2012. E que neste deve-se, segundo Godoy (2013, p. 3), contemplar o gerenciamento integrado, pois até a promulgação da PNRS, os municípios eram os únicos responsáveis pelos RS. A confecção do Plano municipal é condição sine qua non para ter acesso a benefícios e recursos da União (BRASIL, 2010, art. 18), e os dispositivos que regem seu conteúdo mínimo encontram-se no artigo 19 da PNRS.

Sendo assim, o presente artigo tem como objetivo a análise do conteúdo dos PMGIRS da microrregião de Jaboticabal-SP, e suas respectivas interpretações, a luz do artigo 19 da PNRS. Dos dezessete municípios da microrregião, apenas seis são obrigados a elaborar o Plano. Isto por que, municípios com menos de 20.000 habitantes poderão adotar, apenas, planos municipais de "conteúdo simplificado, na forma de regulamento" (BRASIL, 2010, art. 19). Assim, os Municípios estudados são: Bebedouro, Guariba, Jaboticabal, Monte Alto, Pitangueiras e Taquaritinga. Os 


\section{Revista Nacional de}

Gerenciamento de Cidades

planos destes municípios foram obtidos nas Secretarias e departamentos responsáveis pela gestão dos Resíduos Sólidos de cada município, atendendo ao artigo 3o, inciso VI (publicação dos dados e informes de RS) da PNRS (BRASIL, 2010).

\section{2- ANÁLISE DOS PMGIRS DA MICRORREGIÃO DE JABOTICABAL-SP}

O artigo 19 , da Lei $12.305 / 10^{3}$, define o caminho das ações e metas que devem sustentar o PMGIRS, destacando desde a necessidade de diagnóstico dos RS até a definição do gerenciamento da logística reversa. Os Planos dos municípios objetos são apresentados, a partir dos incisos e parágrafos, a seguir.

“I - Diagnóstico da situação dos resíduos sólidos gerados no respectivo território, contendo a origem, o volume, a caracterização dos resíduos e as formas de destinação e disposição final adotadas." (BRASIL, 2010, art. 19, grifo nosso)

Para o diagnóstico dos resíduos, quanto à sua característica física, utiliza-se o método gravimétrico ${ }^{4}$. Segundo Maeda (2013, p. 33), o diagnóstico pode "variar em função de aspectos sociais, econômicos, culturais, geográficos e climáticos, fatores que também diferenciam as comunidades entre si e as próprias cidades". O método é um facilitador do diagnóstico e, assim, um meio de cumprir o solicitado no inciso I.

Os municípios de Guariba, Jaboticabal e Taquaritinga apresentaram seus resultados gravimétricos, o que não foi realizado por Monte Alto e Pitangueiras que fizeram apenas a pesagem dos caminhões. O município de Bebedouro é o único

\footnotetext{
${ }^{3}$ É importante considerar que nessa mesma lei, o artigo 55 define que os planos municipais deveriam entrar em vigor em 02 de agosto de 2012. Dos municípios observados, apenas Bebedouro (2011) e Monte Alto (2012) apresentaram seus planos no prazo. Os Planos dos demais foram apresentados fora do prazo: Pitangueiras (2013), Guariba (2014), Taquaritinga (2014) e Jaboticabal (2015).

${ }^{4} \mathrm{O}$ método gravimétrico é realizado a partir de amostra recolhida dos resíduos urbanos, no qual se faz a medição e a porcentagem de cada resíduo. (MAEDA, 2013)
} 
Revista Nacional de

Gerenciamento de Cidades

que apresenta plano consorciado ${ }^{5}$, com o município de Barretos e, no mesmo, é apresentado apenas o diagnóstico de seu consorciado.

Quanto às formas de destinação e disposição adotadas, os municípios de Bebedouro, Monte Alto e Pitangueiras contratam Aterros terceirizados para esse fim. Guariba, Jaboticabal e Taquaritinga utilizam Aterros municipais, sendo que este é considerado, pelo próprio Plano, como lixão. Quanto ao processo de triagem de resíduos sólidos e seu possível destino, todos os municípios possuem catadores informais, mas apenas Jaboticabal e Monte Alto possuem associação/cooperativa formada. As células do Aterro de Jaboticabal, para a destinação de resíduos orgânicos urbanos e resíduos da construção civil (RCC), são gerenciadas por terceiro(s). Pitangueiras relata que usa Aterro particular para RCC em seu município, mas sem os cuidados adequados, servindo apenas como descarte. Os demais municípios não possuem ou não declararam aterro para RCC. Vale ressaltar que todos destacam a terceirização do descarte e transporte dos resíduos da saúde.

"II - Identificação de áreas favoráveis para disposição final ambientalmente adequada de rejeitos, observado o plano diretor de que trata o $\S 1^{\circ}$ do art. 182 da Constituição Federal e o zoneamento ambiental, se houver." (BRASIL, 2010, art. 19, grifo nosso)

Dos três municípios que possuem Aterro municipal em uso, Guariba, Jaboticabal e Taquaritinga, tem-se que: este último é o que possui situação mais crítica, como relatado; Jaboticabal tem Aterro localizado a $7 \mathrm{~km}$ do centro da cidade, com vida útil de mais 7 anos, se aprovar o projeto para a quarta célula; e Guariba não especifica a localização do Aterro, mas informa que a vida útil prevista é até 2040. Os três destacam em seus Planos, metas de readequação da área. Bebedouro e Monte Alto usam aterros particulares, mas possuem projeto de adequação de área municipal para tal fim. Pitangueiras utiliza aterro particular, tanto

\footnotetext{
${ }^{5} \mathrm{O}$ consórcio intermunicipal é abordado na PNRS. Valoriza os municípios que assim se reúnem na gestão dos RS e lhes dá prioridade no acesso aos recursos da União (BRASIL, 2010, art. 18).
} 


\title{
Revista Nacional de
}

Gerenciamento de Cidades

para resíduos domésticos, de saúde, da construção civil e inertes, e pretende manter a terceirização, por isso não apresenta estudo para identificar tais áreas.

\begin{abstract}
III - Identificação das possibilidades de implantação de soluções consorciadas ou compartilhadas com outros municípios, considerando, nos critérios de economia de escala, a proximidade dos locais estabelecidos e as formas de prevenção dos riscos ambientais. (BRASIL, 2010, art. 19, grifo nosso)
\end{abstract}

Quanto ao consórcio intermunicipal tem-se: o Plano de Consórcio de Bebedouro com Barretos ${ }^{6}$; as intenções de consórcio futuro nos Planos de Jaboticabal e Guariba; e a intenção de Monte Alto criar um consórcio para a compra de um equipamento de trituração e para a construção de uma Usina de Resíduos da Construção Civil, em consórcio com Taquaritinga e Jaboticabal. Taquaritinga não cita intenções e nem identifica possibilidades de futuros consórcios, assim como Pitangueiras. Esta apresenta terceirização de toda a gestão de resíduos, com contratos vigentes. Por isso, declara que "não há relevante interesse da parte do município de Pitangueiras, durante os prazos de vigência de contratos, em estabelecer acordo com outros municípios" (PITANGUEIRAS, 2013, p. 58-59).

\begin{abstract}
IV - identificação dos resíduos sólidos e dos geradores sujeitos a plano de gerenciamento específico nos termos do art. 20 ou a sistema de logística reversa na forma do art. 33 , observadas as disposições desta lei e de seu regulamento, e as normas estabelecidas pelos órgãos do Sisnama ${ }^{7}$ e do SNVS ${ }^{8}$. (BRASIL, 2010, art. 19, grifo nosso)
\end{abstract}

Este inciso estabelece a necessidade de um plano de ação (inclusive sobre Logística Reversa ${ }^{9}$ ) dos municípios para os agentes geradores de resíduos

\footnotetext{
${ }_{7}^{6}$ Barretos não integra a microrregião de Jaboticabal - SP.

${ }^{7}$ Sistema Nacional do Meio Ambiente.

${ }^{8}$ Sistema Nacional de Vigilância Sanitária.

${ }^{9}$ Logística reversa é "instrumento de desenvolvimento econômico e social caracterizado por um conjunto de ações, procedimentos e meios destinados a viabilizar a coleta e a restituição dos resíduos sólidos ao setor empresarial, para reaproveitamento, em seu ciclo ou em outros ciclos produtivos, ou outra destinação final ambientalmente adequada". (BRASIL, 2010, artigo $3^{\circ}$, inciso XII)
} 


\section{Revista Nacional de}

específicos ${ }^{10}$. Os PMGIRS devem identificar os geradores destes resíduos, definir as ações de coleta, transporte e destinação através de planos de gerenciamento. Porém, alguns municípios, por não internalizarem efetivamente a PNRS, se posicionam apenas como fiscalizadores, sem estabelecerem as metas/ações necessárias.

Para os municípios analisados identifica-se que em: Pitangueiras não há a definição, em seu PMGIRS, dos planos de ação e gerenciamento dos resíduos citados, definindo apenas os geradores responsáveis; Bebedouro, os resíduos especiais são abordados de forma vaga e imprecisa; e nos demais municípios há a identificação dos geradores e da necessidade de elaborar o plano de gerenciamento. Vale ressaltar que em Guariba há abordagem, excessiva do poluidor-pagador e do gerador, não sendo claro, no plano, as responsabilidades do município nessa gestão.

Dos Planos dos seis municípios estudados, apenas o de Bebedouro não aborda sobre Logística Reversa, mas, por outro lado, projeta ecopontos para pilhas e baterias. Os demais planos não são claros quanto aos procedimentos a serem utilizados, nem os acordos setoriais que serão necessários, porém todos abordam o tema e definem os resíduos encontrados em seus municípios. Alguns resíduos (pneus, pilhas e lâmpadas) são os mais citados na formação e consolidação de possíveis ecopontos, pois possuem organização mínima de coleta e transporte realizado por seus geradores. Subtende-se que a criação destas áreas é de relevância para o descarte consciente da população, pois o mesmo evita que os resíduos sejam dispensados incorreta e clandestinamente.

\section{V - Procedimentos operacionais e especificações mínimas a serem adotados nos serviços públicos de limpeza urbana e de manejo de Resíduos Sólidos, incluída a disposição final ambientalmente adequada dos rejeitos e observada a Lei $n^{\circ} 11.445$, de 2007. (BRASIL, 2010, art. 19, grifo nosso)}

\footnotetext{
${ }^{10}$ Os resíduos específicos são: construção civil, saúde, agrossilvopastoris, transporte, industriais, mineração, dos serviços de saneamento básico e comerciais e de prestação de serviços não equiparados aos resíduos domiciliares (BRASIL, 2010, art. 20).
} 


\section{Revista Nacional de}

Gerenciamento de Cidades

Todos os Planos apresentam os procedimentos operacionais e especificações mínimas. Guariba, Jaboticabal e Taquaritinga os apresentam em cronogramas, de modo a viabilizar as diretrizes e o planejamento municipal, que serão efetivados até 2033, 2031 e 2034, respectivamente. Bebedouro, Pitangueiras e Monte Alto não fazem menção temporal para cumprimento das mesmas. Vale ressaltar que Monte Alto apresenta o tema como artigo, na Lei de Resíduos Municipal anexado ao Plano.

"VI - Indicadores de desempenho operacional e ambiental dos serviços públicos de limpeza urbana e de manejo de resíduos sólidos". (BRASIL, 2010,

\section{art. 19, grifo nosso)}

A PwC (2011, p. 99) define que "os indicadores são criados para endereçar a necessidade de monitorar e avaliar um determinado processo". São os meios de criar parâmetros para medir desempenho que, segundo o autor, na gestão dos RS, "devem estar alinhados a metas, ações e programas com um horizonte de 20 anos".

Nestes termos, os municípios devem abordar "questões de caráter social, ambiental e econômico" (PwC, 2011, p. 99), mas nem todos contemplam esses tópicos de maneira fidedigna. Bebedouro, Guariba e Monte Alto apenas apresentam metas, porém não propõem indicadores. Jaboticabal, Pitangueiras e Taquaritinga estabelecem indicadores para conduzir a gestão municipal. Convém ressaltar o critério e o cuidado das tabelas de indicadores apresentadas no Plano de Jaboticabal, que se mostram completas e estruturadas.

\footnotetext{
VII - Regras para o transporte e outras etapas do gerenciamento de Resíduos Sólidos de que trata 0 art. 20, observadas as normas estabelecidas pelos órgãos do Sisnama e do SNVS e demais disposições pertinentes da legislação federal e estadual. (BRASIL, 2010, art. 19, grifo nosso)
}

A maioria dos municípios identificou seus geradores, a necessidade do plano de gestão e as regras do transporte. Os Planos de Jaboticabal e Taquaritinga listaram, ainda, problemas encontrados e ações a serem tomadas. O Plano de 


\section{Revista Nacional de}

Gerenciamento de Cidades

Bebedouro trata vagamente sobre os geradores e os meios de transporte e destino destes resíduos.

\section{"VIII - Definição das responsabilidades quanto à sua implementação e} operacionalização, incluídas as etapas do plano de gerenciamento de resíduos sólidos a que se refere o art. 20 a cargo do poder público." (BRASIL, 2010, art. 19, grifo nosso)

Como no inciso anterior, todos os municípios definiram em seus planos as responsabilidades citadas, com exceção do Plano de Bebedouro que aborda imprecisamente sobre resíduos especiais e sobre todo o seu gerenciamento.

\section{"IX - Programas e ações de capacitação técnica voltados para sua} implementação e operacionalização." (BRASIL, 2010, art. 19, grifo nosso)

Os municípios definiram, em seus Planos, os grupos de profissionais (exceção de Monte Alto e Pitangueiras) que desenvolveriam os programas e ações necessárias. Quanto à descrição das atividades, Guariba, Jaboticabal, Monte Alto e Taquaritinga se mostraram criteriosas, o que não foi observado em Bebedouro e Pitangueiras.

" $X$ - Programas e ações de educação ambiental que promovam a não geração, a redução, a reutilização e a reciclagem de resíduos sólidos." (BRASIL, 2010, art. 19, grifo nosso)

Guariba e Monte Alto possuem ações em andamento, junto com as escolas públicas para a orientação e educação ambiental. Pitangueiras admite que, até o momento, a educação ambiental é feita por propagandas e folders administrados pela terceirizada dos serviços de coleta de resíduos domésticos. Contudo, todos os municípios apresentam, em seus Planos, metas e ações para o tema.

XI - Programas e ações para a participação dos grupos interessados, em especial das cooperativas ou outras formas de associação de catadores de materiais reutilizáveis e recicláveis formadas por pessoas físicas de baixa renda, se houver. (BRASIL, 2010, art. 19, grifo nosso) 


\section{Revista Nacional de}

Jaboticabal e Monte Alto possuem associação/cooperativa constituídas em seus municípios, e garantem medidas para fortalecer os acordos existentes. $\mathrm{Na}$ época em que foi elaborado, o Plano de Bebedouro possuía cooperativa, porém a mesma não existe mais. O que chama a atenção, neste Plano, é que cita apenas uma vez a cooperativa, mas não informa as metas e ações conjuntas, para fomentar ou facilitar o trabalho dos catadores cooperados. Guariba e Taquaritinga mostram real interesse, em seus Planos, quanto ao suporte técnico e auxílio para que catadores se unam em cooperativas. Pitangueiras aborda a relevância de inserção de catadores informais, porém não informa programas e ações.

\section{"XII - Mecanismos para a criação de fontes de negócios, emprego e renda,} mediante a valorização dos resíduos sólidos." (BRASIL, 2010, art. 19, grifo nosso)

Os municípios, exceto Monte Alto, esclarecem os benefícios da instalação de unidades de compostagem, transformando os RS em fertilizantes e corretivos ao solo. Bebedouro destaca, ainda, a expectativa em relação a uma Unidade de Recuperação Energética, para futura venda de créditos de carbono em Bolsa de Valores no exterior. Bebedouro, Jaboticabal, Monte Alto e Taquaritinga propõem a instalação de área para beneficiamento dos resíduos da construção civil, que poderá ser usado para pavimentação e confeç̧ão de tijolos, bloquetes e outros. O plano de Monte Alto cita a possibilidade, desta ação, ser consorciada com Jaboticabal e Taquaritinga.Todos os municípios citam a reciclagem de resíduos sólidos, como um gerador de trabalho e renda aos catadores informais.

"XIII - Sistema de cálculo dos custos da prestação dos serviços públicos de limpeza urbana e de manejo de resíduos sólidos, bem como a forma de cobrança desses serviços, observada a Lei n 11.445, de 2007." (BRASIL, 2010, art. 19, grifo nosso)

Todos apresentam algum custo da prestação de serviços tanto municipal quanto de terceiros, uns apresentam alguns valores e outros todo o custo da limpeza urbana. $\mathrm{O}$ que demonstra incompreensão com o inciso, pois não há demonstração 
Revista Nacional de

Gerenciamento de Cidades

do sistema de cálculo e da forma de cobrança, inclusive sobre futuras taxas definidas para o gerenciamento de RS. Exceto o de Pitangueiras, nenhum outro Plano esclarece como será tratada a questão das cobranças, apenas definem sua necessidade. No caso de Pitangueiras há a informação da cobrança dos serviços de limpeza urbana que é debitada diretamente no Imposto Predial e Territorial Urbano (IPTU). O valor é resultado da multiplicação da área construída por $\mathrm{R} \$ 0,72$, mas não é demonstrado como se obtém este valor.

"XIV - Metas de redução, reutilização, coleta seletiva e reciclagem, entre outras, com vistas a reduzir a quantidade de rejeitos encaminhados $\mathrm{p} /$ disposição final ambientalmente adequada." (BRASIL, 2010, art. 19, grifo nosso)

Todos abordam metas, mas apenas Guariba, Jaboticabal e Taquaritinga as demonstram em cronograma de ações ano a ano. Bebedouro as apresenta em ações de curto, médio e longo prazo. Monte Alto e Pitangueiras apenas as apresentam, sem definir temporalidade.

\begin{abstract}
XV - Descrição das formas e dos limites da participação do poder público local na coleta seletiva e na logística reversa, respeitado o disposto no art. 33, e de outras ações relativas à responsabilidade compartilhada pelo ciclo de vida dos produtos. (BRASIL, 2010, art. 19, grifo nosso)
\end{abstract}

Essa descrição é feita por Guariba, Jaboticabal, Pitangueiras e Taquaritinga. Porém, Guariba trata de forma excessiva o poluidor-pagador e o gerador responsável e minimiza a responsabilidade do Poder Público Municipal. Bebedouro cita que, no médio prazo, buscará articular-se com os geradores dos resíduos da logística reversa, porém não esclarece as ações relativas à coleta seletiva. Monte Alto descreve corretamente as ações para a coleta seletiva, contudo, o faz de forma vaga para a logística reversa. 
Revista Nacional de

Gerenciamento de Cidades

XVI - Meios a serem utilizados para o controle e a fiscalização, no âmbito local, da implementação e operacionalização dos planos de gerenciamento de resíduos sólidos de que trata 0 art. 20 e dos sistemas de logística reversa previstos no art. 33. (BRASIL, 2010, art. 19, grifo nosso)

Guariba, Jaboticabal e Monte Alto abordam os meios de controle e fiscalização de ambos. Taquaritinga também os aborda, mas deixa vago pontos dos acordos setoriais da logística reversa. Já Bebedouro e Pitangueiras não abordam meios ou métodos, apenas informam que fiscalizarão o gerenciamento de resíduos.

"XVII - Ações preventivas e corretivas a serem praticadas, incluindo programa de monitoramento." (BRASIL, 2010, art. 19, grifo nosso)

Guariba, Jaboticabal e Taquaritinga identificam os problemas e descrevem as ações de prevenção e correção nos planos de metas. Pitangueiras e Monte Alto descrevem as ações, porém não esclarecem sobre o monitoramento. Bebedouro lista algumas ações, de curto prazo, para recuperar áreas degradadas, mas não cita ações preventivas e de monitoramento.

"XVIII - Identificação dos passivos ambientais relacionados aos resíduos sólidos, incluindo áreas contaminadas, e respectivas medidas saneadoras." (BRASIL, 2010, art. 19, grifo nosso)

Guariba e Jaboticabal propõem identificar e monitorar tais áreas, porém não descrevem sobre sua existência no seu território. Em Bebedouro, o antigo aterro municipal está em desuso e sem medidas saneadoras. Monte Alto identifica pontos de descarte incorretos para os resíduos, e declara metas e ações para o saneamento dessas áreas, sem informar prazos para tal e como será o monitoramento. Em Pitangueiras, a área identificada é do antigo lixão, interditado em 2007, e a Prefeitura informa que medidas saneadoras foram tomadas e aguarda os laudos finais. O Aterro de Taquaritinga é considerado lixão, e as devidas medidas saneadoras estão pautadas no Plano Municipal.

"XIX - Periodicidade de sua revisão, observado prioritariamente o período de vigência do plano plurianual municipal.” (BRASIL, 2010, art. 19, grifo nosso) 


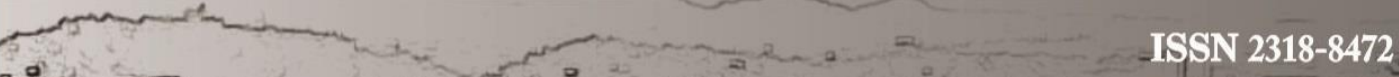

Os municípios, exceto Bebedouro, admitem a necessidade de periodicidade na revisão do Plano. Eles destacam que deve ser a cada quatro anos, quando ocorre o plano plurianual municipal, porém informam que a primeira adequação pode ocorrer em prazo inferior.

$\S 4^{\circ} \mathrm{A}$ existência de plano municipal de gestão integrada de resíduos sólidos não exime o município ou o Distrito Federal do licenciamento ambiental de aterros sanitários e de outras infraestruturas e instalações operacionais integrantes do serviço público de limpeza urbana e de manejo de RS pelo órgão competente do Sisnama. (BRASIL, 2010, art. 19, grifo nosso)

Jaboticabal é o único que possui Aterro Municipal devidamente licenciado (gerido por empresa contratada), contudo a viabilização de projeto para implementar a Central de Gestão de Resíduos, em seu Plano, depende de novos licenciamentos. Os aterros terceirizados que Monte Alto contrata, possuem suas licenças. O Aterro de Guatapará, terceirizado por Bebedouro e Pitangueiras é licenciado. Assim como o aterro terceirizado para resíduos da saúde por Pitangueiras, porém o Aterro particular usado para a construção civil e para inertes não possui as licenças citadas, pois estão em avaliação. O Aterro usado por Guariba e Taquaritinga não são licenciados.

\begin{abstract}
$\S 5^{\circ} \mathrm{Na}$ definição de responsabilidades na forma do inciso VIII do caput deste artigo, é vedado atribuir ao serviço público de limpeza urbana e de manejo de resíduos sólidos a realização de etapas do gerenciamento dos resíduos a que se refere o art. $20 \mathrm{em}$ desacordo com a respectiva licença ambiental ou com normas estabelecidas pelos órgãos do Sisnama e, se couber, do SNVS. (BRASIL, 2010, art. 19, grifo nosso)
\end{abstract}

Os municípios se mostram cientes de seu papel na definição de responsabilidades e no estabelecimento de acordos setoriais, bem como da confecção dos planos de gerenciamento por resíduos. Vale ressaltar que em Bebedouro estes pontos são tratados de forma superficial. 
Revista Nacional de

Gerenciamento de Cidades

$\S 6^{\circ}$ Além do disposto nos incisos I a XIX do caput deste artigo, o plano municipal de gestão integrada de resíduos sólidos contemplará ações específicas a serem desenvolvidas no âmbito dos órgãos da administração pública, com vistas à utilização racional dos recursos ambientais, ao combate a todas as formas de desperdício e à minimização da geração de resíduos sólidos. (BRASIL, 2010, art. 19, grifo nosso)

Apenas Monte Alto e Taquaritinga abordam sobre a responsabilidade municipal de separar seus resíduos na fonte geradora dos órgãos públicos.

$\S 9^{\circ}$ Nos termos do regulamento, o município que optar por soluções consorciadas intermunicipais para a gestão dos RS, assegurado que o plano intermunicipal preencha os requisitos estabelecidos nos incisos I a XIX do caput deste artigo, pode ser dispensado da elaboração de plano municipal de gestão integrada de resíduos sólidos. ${ }^{11}$ (BRASIL, 2010, art. 19, grifo nosso)

O único município que fez a opção pelo plano consorciado foi Bebedouro juntamente com Barretos.

A partir da análise dos incisos e parágrafos do artigo 19, da PNRS, confrontados com os Planos municipais da microrregião de Jaboticabal, pôde-se evidenciar ponderações e inferências. No caso do Plano de Bebedouro, único Consórcio na microrregião, observou-se que o Plano favorece o município de Barretos em detrimento do município de Bebedouro. Além disso, o plano é vago, mal elaborado, com tópicos confusos, o que compromete a compreensão do texto; e não transparece as atividades de responsabilidade do Poder Público Municipal.

Em Guariba, o Plano não difere das faltas destacadas no plano anterior, apresentando, ainda, visível cunho político. Isto se evidência por valorizar excessivamente o gestor do município no período de elaboração do Plano. Destaca

\footnotetext{
${ }^{11}$ É importante destacar que os parágrafos $1^{\circ}, 2^{\circ}, 3^{\circ}, 7^{\circ}$ e $8^{\circ}$, da PNRS, não foram abordados, pois: os três primeiros são para municípios com menos de vinte mil habitantes; o $\S 7^{\circ}$ informa que o conteúdo do plano deve ser disponibilizado na plataforma de dados do Sistema Nacional de Informações sobre a Gestão dos Resíduos Sólidos (SINIR); e o § $8^{\circ}$ trata sobre a inexistência do plano, mas como todos os municípios citados os possuem, esse parágrafo foi desconsiderado.
} 
Revista Nacional de

Gerenciamento de Cidades

de forma demasiada a discussão sobre poluidor-pagador e de gerador responsável, em detrimento do papel do Poder Público Municipal na gestão. Aborda, principalmente, metas de curto prazo, o que pode inviabilizar o Plano.

O Plano de Jaboticabal é o mais conciso e o que aborda os incisos e parágrafos, da PNRS, de maneira clara e precisa. Apresenta tópicos com as carências e as deficiências municipais, o que enriquece o texto e a análise. Além disso, utiliza tabelas e imagens que favorecem a compreensão. Porém, o Plano é o único que, até a finalização do artigo, não tinha sido aprovado pela Câmara Municipal.

Monte Alto se antecipou a todos, pois desde 2012 já possui Lei Municipal que institui o Plano. É importante ressaltar que esta Lei faz parte do anexo do PMGIRS. No corpo do texto do Plano, também, é apresentado a Lei de Saneamento e a PNRS na íntegra, o que resulta num plano longo. As metas e ações estão descritas na forma de artigo, na Lei Municipal, o que dificulta a análise das informações no texto principal do PMGIRS. Observam-se, ainda, conceitos e parágrafos repetitivos. Por outro lado, apresenta tabelas e imagens que favorecem a compreensão do Plano.

O PMGIRS de Pitangueiras apresenta muitas definições, mas poucas inferências sobre a real situação do Município, o que torna o Plano superficial. O gerenciamento do RS é quase todo terceirizado e esta situação se apresenta, no Plano, por tempo indeterminado.

O PMGIRS de Taquaritinga, confeccionado apenas em 2014, é extenso, com muitas definições, mas com boas inferências sobre a situação municipal. $O$ Plano apresenta tópicos onde são: destacados os problemas do município; e estabelecidas metas para sanar os problemas, o que o valoriza.

É importante considerar, ainda, que apenas os planos de Jaboticabal e Taquaritinga foram elaborados por técnicos da Administração Pública, enquanto os demais por empresas terceirizadas. 
Revista Nacional de

Assim, a análise dos PMGIRS da microrregião de Jaboticabal apresenta resultados similares aos destacados por Godoy (2013) e Gomes e Steinbrück (2012), visto que há posicionamentos díspares entre o entendimento da Lei e a sua aplicação nos municípios, inclusive quanto aos prazos legais não cumpridos, a não fiscalização e a não responsabilização efetiva dos geradores.

\section{3- CONSIDERAÇÕES FINAIS}

Através do escopo deste artigo pôde-se inferir a dificuldade de interpretação, posicionamento e aplicação da PNRS nos municípios analisados. Ainda há conceitos cristalizados, inclusive com o não comprometimento da gestão municipal em relatar criteriosamente a realidade de seu município para que as devidas ações sejam implementadas, o que evidencia a importância de se ter pessoal especializado e recursos materiais e financeiros para viabilizar o plano. Isso também pôde ser observado visto que apenas Jaboticabal e Taquaritinga elaboraram o PMGIRS, com seu corpo técnico, mas fora do prazo legal. Por outro lado, Bebedouro e Monte Alto que apresentaram planos elaborados por terceiros, atenderam o prazo limite.

Com isso, as falhas observadas nos planos podem ser um indicativo da dificuldade de análise e de constituição de corpo técnico especializado, bem como uma incapacidade ou desconsideração do Poder Público quanto a real importância dessa temática, obstando, assim, a construção de um conhecimento municipal sobre resíduos sólidos.

\section{4- REFERÊNCIAS BIBLIOGRÁFICAS}

BRASIL. Lei $n^{\circ} 12.305$, de 2 de agosto de 2010. Institui a Política Nacional de Resíduos Sólidos; altera a Lei $n^{\circ}$ 9.605, de 12 de fevereiro de 1998; e dá outras providências. Diário Oficial [da] República Federativa do Brasil, Brasília, DF. 2010. Disponível em: <http://www.planalto.gov.br/ccivil_03/_ato20 07-2010/2010/lei/l12305. htm> Acesso em 15 Mar. 2015. 


\section{Revista Nacional de}

Gerenciamento de Cidades

BEBEDOURO. SIGEINRES - Consórcio Intermunicipal para a Gestão Integrada de Resíduos Sólidos. Plano de Saneamento de Resíduos Sólidos e Manejo de Resíduos. Barretos - SP, 2011. 128 f.

BERNARDES, Márcio de Souza. Os desafios para efetivação da Política Nacional de Resíduos Sólidos frente a figura do consumidor-gerador. Revista Eletrônica do Curso de Direito - UFSM, v. 8, p. 195-207, 2013.

GODECKE, Marcos Vinícius; NAIME, Roberto Harb; FIGUEIREDO, João Alcione Sganderla. 0 consumismo e a geração de resíduos sólidos urbanos no Brasil. Revista Eletrônica em Gestão, Educação e Tecnologia Ambiental, v. 8, n 8, p. 1700-1712, set-dez, 2012.

GODOY, Manuel Rolando Berríos. Dificuldades para aplicar a Lei da Política Nacional de Resíduos Sólidos no Brasil. Caderno de Geografia, v. 23, n³9, p. 1-12, 2013.

GOMES, Eduardo R.; STEINBRÜCK, Melissa Abla. Oportunidades e dilemas do tratamento dos resíduos sólidos no Brasil à luz da Política Nacional de Resíduos Sólidos (Lei N. 12.301/10). Confluências, vol. 14, n 1. Niterói: PPGSD-UFF, p. 100-114, 2012.

GUARIBA. Prefeitura Municipal de Guariba. Plano Integrado de Gestão de Resíduos Sólidos de Guariba - SP, Guariba - SP, 2014. 139 f.

MAEDA, Elcio Eiti. Diagnóstico da Gestão de Resíduos Sólidos nos municípios do Estado de São Paulo, a partir dos Planos Municipais de Gestão Integrada. 2013. 160 f. Dissertação de Mestrado. Universidade de São Paulo - Pós-Graduação em Engenharia Hidráulica e Saneamento, São Carlos.

JABOTICABAL. Prefeitura Municipal de Jaboticabal. SAAEJ - Serviço Autônomo de Água e Esgoto de Jaboticabal e $S A A M A$ - Secretaria de agricultura, abastecimento e meio ambiente de Jaboticabal. Plano Municipal de Gestão Integrada de Resíduos Sólidos de Jaboticabal, Jaboticabal - SP, 2015 (em processo de aprovação). $97 \mathrm{f}$.

MONTE ALTO. Plano Municipal de Gerenciamento Integrado de Resíduos Sólidos de Monte Alto - SP. Monte Alto - SP, 196 f. (Elaborado por PROJECTA, Assessoria e Consultoria)

PwC. Pricewaterhousecoopers. Guia de orientação para adequação dos Municípios à Política Nacional de Resíduos Sólidos (PNRS). São Paulo, 2011.

PITANGUEIRAS. Plano Municipal de Gestão Integrada de Resíduos Sólidos de Pitangueiras/SP. Pitangueiras - SP, 2013. 105 f. (Elaborado por SANETECH. Sanetech Engenharia e Meio Ambiente Ltda).

TAQUARITINGA. Prefeitura Municipal de Taquaritinga. Plano Municipal de Gestão Integrada de Resíduos Sólidos - PMGIRS, Taquaritinga - SP, 2014. 231 f. 